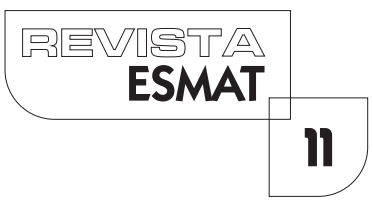

\title{
NUEVAS EXPERIENCIAS DE DESARROLLO DE LAS PRÁCTICAS DE INFORMACIÓN DE LOS DERECHOS HUMANOS EN PARAGUAY
}

NEW EXPERIENCES FOR THE DEVELOPMENT OF HUMAN RIGHTS INFORMATION PRACTICES IN PARAGUAY

Julia Helena Fernández Albertini

Coordinadora de la Dirección de Derechos Humanos de la Corte Suprema de Justicia de Paraguay

\section{RESUMEN}

La información es el puntapié inicial del acceso a la Justicia, ambos derechos humanos fundamentales, especialmente para las personas en situación de vulnerabilidad. El proceso democrático latinoamericano ha madurado hacia la formalización de este derecho en leyes nacionales, en diversos instrumentos declarativos, y en jurisprudencia internacional, como ser el caso Claude Reyes y otros vs. Chile en el ámbito del sistema interamericano de protección de los Derechos Humanos. Considerando esto, la Corte Suprema de Justicia de Paraguay, acompaña un proceso país de cambios estructurales referidos al acceso a la información, un despertar ciudadano y una nueva ley que reglamenta la Carta Magna. Desde el organismo judicial se cuenta con acciones concretas y fundamentales como el Acuerdo y sentencia $N^{\circ} 1306$ y el desarrollo de políticas institucionales de procesamiento de información orientadas a la transparencia, la toma informada de decisiones y por sobre todo, con una mirada distinta, en la que el centro, son las personas.

PALABRAS CLAVE: Información; Acceso; Justicia; Transparencia; Indicadores; Toma de decisiones; Persona; Derechos humanos; Democracia.

\section{ABSTRACT}

Information is the starting point of access to justice, both fundamental human rights, especially for people in conditions of vulnerability. Latin American democratic process has matured towards the formalization of this right in national laws, in various declarative instruments, and in international jurisprudence, such as Claude Reyes versus Chile in the 
area of the interamerican system for the protection of Human Rights. Considering this, Paraguay Supreme Court of Justice accompanies a country process of structural changes related to the access of information, a citizen awakening for a new law that rules the Magna Carta. The judicial body has concrete and fundamental actions such as Agreement and Judgment No. 1306 and the development of institutional policies for information processing aimed at transparency, informed decision making and above all, with a different look, in wich people are considered the central issue.

KEYWORDS:Information; Access; Justice; Transparency; Indicators; Decision making; Person; Human rights; Democracy.

Al iniciar la reflexión sobre el tema en cuestión, resulta indispensable definir el acceso a la información en el contexto actual y como requisito para los Estados Democráticos.

El reconocimiento del acceso a la información como derecho humano ha evolucionado progresivamente hasta consagrarse en una premisa fundamental para la transparencia en la gestión pública y un requisito para validar los sistemas democráticos comotales.

Esta herramienta se ha desarrollado junto con las transiciones democráticas instalándose en las Constituciones Nacionales y muy posteriormente en leyes de acceso a la Información. Paralelamente el sistema interamericano de derechos humanos, desde sus inicios lo ha mencionado como parte del catálogo de derechos, en la Declaración Americana de los Derechos y Deberes del Hombre, cuyo artículo IV establece que:

"Toda persona tiene derecho a la libertad de investigación, opinión, expresión y difusión del pensamiento por cualquier medio".

Posteriormente, en 1969 se suscribe la Convención Americana sobre Derechos Humanos. En el numeral I del artículo 13 del mencionado instrumento claramente se expresa que:

“Toda persona tiene derecho a la libertad de pensamiento y de expresión. Este derecho comprende la libertad de buscar, recibir y difundir informaciones e ideas de toda índole, sin consideración de fronteras, ya sea oralmente, por escrito o en forma impresa o artística, o por cualquier otro procedimiento de su elección."

A partir de estos artículos mencionados tanto la Asamblea General de la OEA, como los órganos del Sistema Interamericano de Protección de los Derechos Humanos, Comisión y Corte Interamericanas, han dado un amplio contenido al derecho a la libertad de pensamiento y de expresión, que a su vez enmarca al derecho a la información pública. Resoluciones de la Asamblea General, la creación de una relatoría de la libertad de expresión en la Comisión Interamericana de Derechos Humanos en el año 2007, la Declaración de principios sobre libertad de expresión en el año 2000, son 
eventos que hoy resultan fundamentales en el debate internacional, así como en los fallos del sistema.

Uno de estos fallos, el más paradigmático tal vez es el del caso Claudio Reyes y otros vs. Chile ante la Corte Interamericana. El caso trataba de la negativa de una institución del Estado a brindar a las víctimas toda la información que requerían sobre un proyecto de deforestación con impacto ambiental. La Comisión sostuvo que dicha negativa, así como la falta de un recurso judicial efectivo para impugnarla, generaban la responsabilidad internacional del Estado por la violación del derecho a la libertad de pensamiento y de expresión y del derecho a la protección judicial. La sentencia del I 9 de septiembre de 2006, sienta una jurisprudencia clara y precisa, e incorpora estándares y reconoce expresamente que el derecho de acceso a la información es un derecho humano integrante del derecho a la libertad de pensamiento y de expresión.

Desde 1946 la Asamblea General de la Organización de las Naciones Unidas trabajó con el concepto de libertad de información. En su Resolución 59 (I) de 1946 la Asamblea General afirmó que:

"la libertad de información es un derecho humano fundamental y [...] la piedra angular de todas las libertades a las que están consagradas las Naciones Unidas" y que abarca "el derecho a juntar, transmitiry publicar noticias".

Por su parte el artículo 19 del Pacto Internacional de Derechos Civiles y Políticos (PIDCP) adoptado en 1966 y vigente desde 1976, establece que:

"Toda persona tiene derecho a la libertad de expresión; este derecho comprende la libertad de buscar, recibir y difundir informaciones e ideas de toda índole, sin consideración de fronteras, ya sea oralmente, por escrito o en forma impresa o artística, o por cualquier otro procedimiento de su elección."

En 1993 es creada la Relatoría Especial para la Libertad de Opinión e Información de la $\mathrm{ONU}$ que ha desarrollado el concepto en el sistema de Naciones Unidas. Ambos sistemas albergan en sus textos y decisiones, posturas y alcances similares. Es destacable que derecho al acceso a la información es tratado de manera análoga en el ámbito del sistema africano de protección, la Unión Europea y el Consejo de Europa, entre otros.

El proceso paraguayo, se inicia en los debates de la Constitución de 1992. Los convencionales constituyentes atendiendo a la nueva era de libertades consagran en el art. 28 de la nueva Carta Magna:

"Las fuentes públicas de información son libres para todos. La ley regulará las modalidades, plazos y sanciones correspondientes a las mismas, a fin de que este derecho sea efectivo".

La necesidad de contar con una regulación al texto constitucional, así como una serie 
de hechos sociales creó en los últimos años un ambiente favorable para el debate sobre el acceso como herramienta ciudadana de ejercicio democrático y anticorrupción.

El I 8 de septiembre la Ley No. 5.282 "De Libre Acceso Ciudadano a la Información Pública y Transparencia Gubernamental”, que reglamenta el art. 28 de la CN. supra mencionado. El instrumento normativo obliga a las instituciones estatales y a los funcionarios a divulgar la información de carácter público solicitada por los ciudadanos, con mínimas limitaciones de acceso, que al ser aplicadas para una negativa, deben ser debidamente fundamentadas por el órgano gubernamental según lo establecido. Agrega que ninguna disposición podrá ser entendida o utilizarse para negar, menoscabar o limitar la libertad de expresión, la libertad de prensa o la libertad de ejercicio del periodismo.

El reconocimiento del acceso como derecho humano implica también la necesidad de garantizarlo a través de una protección judicial adecuada, para que de forma rápida y expedita se pueda obtener su protección. Ante esta necesidad la Corte Suprema de Justicia crea la oficina de Derechos Humanos fue creada por Resolución No 759/2000, como organismo técnico administrativo especializado de la Corte Suprema de Justicia, con la denominación Unidad de Derechos Humanos UDH, con funciones de Monitoreo, Información, Investigación, Análisis y Difusión. Estas funciones que fueron ampliadas (Acta No 3 I/2002 Sesión del Pleno de la CS) que aprueba el Plan Estratégico 2002/2005 UDH) con las tareas de Asesoría Técnica, Articulación y Promoción en Capacitación. A partir del año 2006, por medio del Acta Nro. 3 fue convertida en Dirección de Derechos Humanos, considerando como áreas temáticas prioritarias: niñez y adolescencia, género, indígena y área internacional. En el año 2010 , la Dirección de Derechos Humanos restructura su organización en cuatro Programas de trabajo Acceso a la justicia, Políticas Judiciales, área internacional y Planificación.

Refuerza esta política de Derechos Humanos, la adopción de medidas concretas como la creación del Museo de la Justicia y Centro de Documentación y Archivo para los Derechos Humanos en el año 1993, la creación de la Secretaría de Género en el año 2010 y la adopción de las Reglas de Brasilia como lineamiento madre de la administración de justicia a través de la Acordada Judicial Nº 633.

Paralelamente, el Poder Judicial del Paraguay introduce como mandato en el marco del Plan Estratégico institucional 20 I I/20 I5, dos relevantes objetivos estratégicos que lo llevan a cumplir con ese cometido:

O.E.5: Fortalecer la comunicación interna y externa efectiva del Poder Judicial, y posicionarlo como poder del Estado eficaz en el cumplimiento de su misión y transparente en su accionar ante la ciudadanía.

O.E.6:Difundir y controlar la vigencia de los derechos humanos en las políticas, sentencias, normativas y el accionar del Poder Judicial, y rendir al respecto a la ciudadanía y a los foros que corresponda. 
A partir de estos lineamientos se han desarrollado acciones tanto en la labor jurisdiccional como en la estratégica de apoyo tendientes a un gobierno judicial transparente y respetuoso de los derechos humanos.

Al respecto, la jurisprudencia paraguaya, ha introducido en sus resoluciones en forma progresiva, las directrices jurisprudenciales trazadas por la Corte Interamericana. Esto, se puede ilustrar mejor tomando como ejemplo concreto el Acuerdo y Sentencia del plenario de la Corte Suprema de Justicia en el Paraguay en materia de derecho a la información. En dicho fallo, de fecha I 5 de octubre de 2013, se declara el derecho de las personas a procurar, acceder y recibir información pública o producida por instancias públicas, con carácter de derecho fundamental:

"reconoce el derecho de las personas a recibir información veraz, responsable y ecuánime. Las fuentes públicas de información son libres para todos",

y declara:

"la obligación positiva del Estado de suministrarla, de forma tal que la persona pueda tener acceso a conocer esa información o reciba una respuesta fundamentada cuando por algún motivo permitido por la Convención el Estado pueda limitar el acceso a la misma para el caso concreto. [...].

Según el fallo, la información debe ser entregada sin necesidad de acreditar un interés directo para su obtención o una afectación personal, salvo en los casos en que se aplique una legítima restricción; en el mismo documento se indica: "los datos personales patrimoniales pueden ser publicados o difundidos cuando consten en las fuentes públicas de información", sin que se pueda aludir al derecho a la intimidad para evitar su acceso.

Existe además un antecedente en los tribunales paraguayos, que data del año 2008, en el que el tribunal de apelaciones civil y comercial de la tercera sala, a través de su Ac. y Sent. $N^{\circ} 5$, sostiene:

“Este derecho [a la información] encuentra su justificación en el derecho más genérico, esencial a las democracias deliberativas y participativas, de formar libremente las opiniones y participar de modo responsable en los asuntos públicos; contribuye a la formación de la opinión propia y la pública, que está estrechamente ligada al pluralismo político. Se constituye así en un instrumento [...] que condiciona la participación en el manejo de 'lo público'”, "comprende tanto el de buscar, como el de recibir e incluso difundir la información obtenida", y que es un derecho que "se tiene y se justifica por sí mismo, según las finalidades genéricas de participación y control que se dan en la vida democrática, y no en relación con una motivación específica". 
Otro punto a destacar, es que el presentes fallo de la Corte Suprema de Justicia de Paraguay no solo ha delimitado el alcance del acceso a la información, sino que lo hace haciendo expresa mención de un "control de convencionalidad" respecto a la aplicación de los derechos en estudio. Este hecho se constituye de fundamental trascendencia para la aplicación del derecho internacional de los derechos humanos en Paraguay al sentar jurisprudencia de la obligación del Estado de la aplicación de la doctrina y los instrumentos internacionales de protección de los derechos humanos.

El sentido de estos fallos demuestra que la Corte Suprema de Justicia del Paraguay se ha propuesto transversalizar a los Derechos Humanos en todas las acciones que hacen a la administración de justicia.

Otro mecanismo que ha encontrado la CSJ de Paraguay para lograr una utilización de la información respetuosa de los Derechos Humanos, es la formulación de un sistema de "Indicadores de juicio justo del Poder Judicial de la República del Paraguay". El llamado de alerta sobre la necesidad de contar con información estadística con enfoque de derechos se produce cuando la Dirección de Derechos Humanos participa en la actualización de los informes a Órganos de tratados y la elaboración del Examen Periódico Universal. Durante todo el año 2010, periodo en el que se elaboran las respuestas estatales, se visualiza la ausencia de información pertinente, así como el hecho de que la información disponible tenía un enfoque que registraba procesos y no personas.

A partir de esto y teniendo como guía, el proceso iniciado por el Tribunal Superior de Justicia del Distrito Federal de México, que compartió su experiencia en el desarrollo del proceso de construcción de indicadores, la Corte Suprema de Justicia de la República del Paraguay impulsa la creación de su matriz de indicadores. Para dicho emprendimiento se contó con el apoyo de la Asesora en Derechos Humanos de las Naciones Unidas para Paraguay, la coordinación de la Dirección de Derechos Humanos y la participación comprometida de la Dirección General de Recursos Humanos, la Dirección General de Garantías Constitucionales, la Dirección de Planificación y Desarrollo, la Dirección de Estadística Judicial, la Dirección de Informática y Tecnología, la Dirección Centro de Documentación y Archivo, y representantes del Área Jurisdiccional. Se recibió el asesoramiento especializado de la UNICEF Paraguay y del Fondo Especial del Protocolo Facultativo de la Convención Contra la Tortura.

Los indicadores de juicio justo recogen los estándares mínimos establecidos por los Tratados y convenciones internacionales de derechos humanos, así como los establecidos por las 100 reglas de Brasilia de acceso a la justicia de personas en situación de vulnerabilidad, instrumento de soft law que fue efectivamente incorporado a la labor de los operadores judiciales del Paraguay a través de la Acordada No 633 de la CSJ.

Las reglas de Brasilia, en su regla No 92, establecen la necesidad de que el gobierno judicial asuma el compromiso de promover investigación y estudios en materia de acceso a la justicia. Partiendo de esa base, la Corte Suprema de Justicia a través de la Dirección de Derechos Humanos, desarrolla los indicadores de juicio justo como una 
manera de identificar y cuantificar el acceso a la justicia de grupos en situación de vulnerabilidad.

La instalación del Sistema de Indicadores de Derechos Humanos posiciona a Paraguay como el primer país latinoamericano en elaborar indicadores judiciales y es un proceso que se inicia en el año 2012 con el diseño de la Matriz. El documento, incluye la descripción y fundamentos para cada indicador diseñado, e incorpora progresivamente la publicación de resultados según la disponibilidad de información a corto, mediano y largo plazo. Se culminará con la publicación de los resultados de la totalidad de indicadores en el año 20 I 5, momento en el que se diseñará el próximo Plan Estratégico de la Corte Suprema de Justicia de la República del Paraguay y se inicia la elaboración del nuevo Examen Periódico Universal de Paraguay.

La matriz cuenta con indicadores estructurales, de proceso y de resultado y es de alcance nacional. Su formulación fue validada por todas las Circunscripciones Judiciales de la República. Incluye de manera novedosa, atributos sobre Garantías Procesales Constitucionales y Protección Especial de Niñas, Niños y Adolescentes. Así mismo es la primera vez que un gobierno cuenta con indicadores propios de condiciones de vida y procesales de personas privadas de libertad por orden judicial y herramientas estandarizadas para la recolección de esa información que a su vez se convierte en un sistema de prevención contra la tortura. Para esto, se contó con la colaboración del Fondo de Prevención de la Tortura de Naciones Unidas (OPCAT). La matriz además, permite generar información sobre los principios de accesibilidad, igualdad y no discriminación, y como aspectos vinculados con la rendición de cuentas a la ciudadanía y la transparencia.

Los indicadores atienden distintas desagregaciones, según diversos criterios como edad, sexo, género, origen étnico, estatus socioeconómico o lugar de residencia, entre otros. A través de ellos se busca analizar el acceso a los derechos humanos en el sistema de justicia, al derecho a un juicio justo con las debidas garantías judiciales por parte de personas y grupos específicos. Sirven de contrapeso a informes y datos estadísticos como número de casos y expedientes, sentencias pronunciadas o tipo de delitos, que no necesariamente informan sobre las actuaciones en cuanto al acceso y el goce de derechos.

Los resultados que hoy brinda la herramienta son fundamentales para el análisis estratégico que permite visibilizar a las personas entre los expedientes y contribuir directamente a minimizar la posibilidad de que por acción u omisión de la administración de justicia se produzcan quiebres en el proceso y el resultado de la administración de justicia.

La herramienta a su vez, da efectivo cumplimiento a los mandatos establecidos en el objetivo estratégico $N^{\circ} 5$ de transparencia, además del $N^{\circ} 6$ de difundir y controlar la vigencia de los derechos humanos en el accionar judicial y rendición de cuentas en los fueros que corresponda. Esto redunda en una perspectiva de Derechos Humanos en la Administración de Justicia que atiende un trabajo judicial focalizado en personas en 
contraposición a la visión tradicional de procedimientos y plazos procesales, y a su vez, visibilizando a quienes forman parte del proceso, también permiten aprender de cada intervención para promover soluciones efectivas, fortalecen la aplicación efectiva de la ley y de los compromisos internacionales de DDHH e impulsan al trabajo innovador y colaborativo.

Por último, es necesario recordar que la información, es una herramienta bastante menospreciada en los sistemas estatales, sumidos en la opacidad y la mecanización de procesos. La misma es fundamental en términos de rendición de cuentas a la ciudadanía de un país, así como a las instancias internacionales de supervisión de derechos humanos. Paraguay, a través del fallo sobre el acceso a la información y control de convencionalidad, y el desarrollo de indicadores de derechos humanos ha iniciado un camino decisivo que ya ha podido erigirse en una serie de buenas prácticas comenzando a ser compartida con otros países de la región y el mundo.

Todo el camino emprendido por la CSJ de Paraguay encuentra su fin último en la búsqueda del acceso efectivo a una justicia, a través de la información como un instrumento que lleve a una profunda transformación social y cultural, y aborde las reformas que sean necesarias para garantizar la plena vigencia de los derechos y libertades fundamentales del país y su democracia.

\section{REFERENCIAS}

Relatoría especial para la libertad de expresión. (2007). Estudio Especial sobre el derecho al acceso a la información. I 8/04/I 5, de Comisión Interamericana de derechos

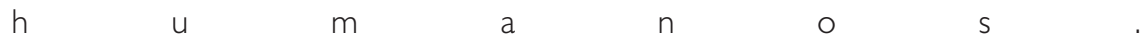
<http://cidh.oas.org/relatoria/section/Estudio\%20Especial\%20sobre\%20el\%20dere cho\%20de\%20Acceso\%20a\%20la\%20Informacion.pdf>.

Acuerdo y sentencia No 1306 del 15 de Octubre de 2013 de la Corte Suprema de Justicia de Paraguay.

Acordada N 633, I 00 Reglas de Brasilia de acceso a la Justicia a personas en situación de vulnerabilidad.

Plan Estratégico Institucional 20 | | -20 I 5.

Corte Suprema de Justicia, Paraguay - Naciones Unidas, Paraguay. (20 I3). Indicadores sobre el derecho a un juicio justo en el Poder Judicial de la República del Paraguay. Asunción: LITOCOLORSRL. 
NUEVAS EXPERIENCIAS DE DESARROLLO DE LAS PRÁCTICAS DE INFORMACIÓN DE LOS DERECHOS HUMANOS EN PARAGUAY

Dirección de Derechos Humanos CSJ. (20/3). Políticas y acciones principales desarrolladas por la Dirección de Derechos Humanos. Asunción - Paraguay: Servicios Gráficos del Poder Judicial.

Caso Claude Reyes y otros Vs. Chile. Sentencia de 19 de septiembre de 2006, Corte Interamericana de Derechos Humanos.

Principios de Lima sobre el acceso a la Información, Lima año 2000.

Declaración de principios de la OEA sobre libertad de expresión. Aprobada durante el $108^{\circ}$ período ordinario de sesiones de la CIDH. Octubre, 2000.

Declaración de Chapultepec. Adoptada por La Conferencia Hemisférica sobre Libertad de Expresión celebrada en México, D.F., marzo de 1994.

Convención Americana de Derechos Humanos. (Pacto de San José). San José, 1969.

Recebido em: 14/07/2015

Aprovado em: 13/09/2016 